Nuclear winter

\section{US plans for studies proliferate}

\section{Washington}

A \$50 MILLION five-year national research plan for studying "nuclear winter" possible global cooling following nuclear war - has been drawn up by the National Oceanic and Atmospheric Administration (NOAA). A final draft is now being circulated to an inter-agency review committee before being sent to the White House's Office of Science and Technology Policy (OSTP) by the end of October.

The study plan has been drawn up at OSTP's request by a group headed by Alan Hecht, director of NOAA's National Climate Program Office. It seeks to reduce the principal uncertainties associated with nuclear winter by co-ordinated research in several different areas. The $\$ 50$ million price tag corresponds to one of several options put forward by NOAA: if the Office of Management and Budget accepts all the study proposals, the cost could be considerably higher. The nominal five years' duration could be extended as necessary.

The proposed study places the highest priority on understanding source inputs of smoke into the atmosphere. Laboratory and field experiments with different fuels would be performed to gain information about the size distribution of smoke particles and their optical properties. Other studies would be designed to investigate how the results from small-scale experiments can be scaled up, first to room size, then to building size and finally to large areas. Ultimately, there would be field

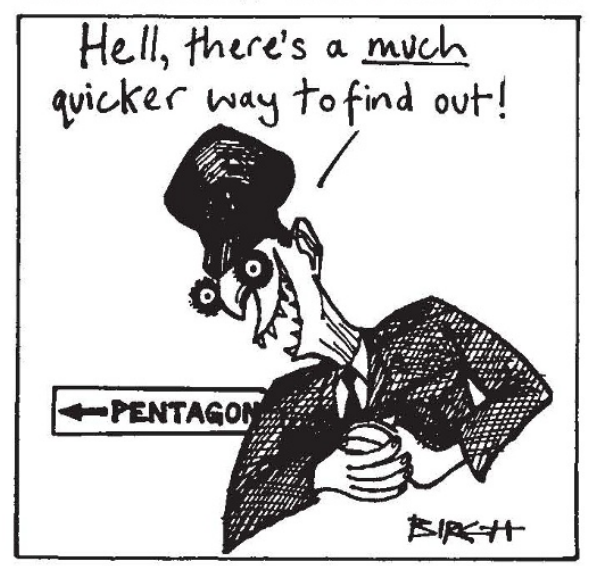

experiments entailing managed forest fires instrumented to measure the composition of smoke below, within and above clouds and what happens at the smoke/cloud interface. Some experiments would use areas of clear-felled vegetation.

The number of managed burns the draft plan says, could be contained by studying natural forest fires provided that it is possible to respond rapidly enough in moving equipment and personnel, but some field experiments are thought inevitable. As well as the experimental work, there would be a strengthened modelling effort focusing on further development of mesoscale and cloud models. Optional extras in the plan include studies of the natural transport of Sahara dust and Arctic haze. Also in the high-cost option is work on the biological impact of global temperature changes.

Already, the Department of Energy and the Defense Nuclear Agency (DNA) are managing theoretical studies of nuclear winter. The DNA programme has been allocated $\$ 1.5$ million in this financial year and will be increased next year; it will be integrated into the national study if and when that is accepted, when DNA may manage some of the work. But, according to Dr C. Gillespie of DNA, the agency's own work is well under way and will not wait for the national plan. DNA concentrates on the chemistry of smoke and on developing modified three-dimensional global climatic models suitable for nuclear winter studies. It also examines likely explosion scenarios and sponsors policy research. All the scientific work, like that in the national programme, will be published in the open literature. Gillespie says the only thing clear so far is that the problems are extremely complex.

Academic scientists who have helped plan this study are pleased by the "unusually good co-operation" and the "non-combative attitude" of government officials from all departments. One commented that nuclear winter is a rare example of an area where disagreements between scientists are noisier than those between bureaucrats. But he fears that the administration may seek to use the scientific uncertainties as an excuse to respond only by commissioning research.

Whatever the political complexion of the administration after November's presidential election, a request for some $\$ 50$ million of new money over five years will need some justifying. The approval of the President's science adviser (Dr George Keyworth) will be but the first step.

Meanwhile, Congress's Office of Technology Assessment (OTA) is also likely shortly to announce studies connected to nuclear winter. Three broad possibilities are being discussed: a general assessment of what is known about the long-term effects of nuclear war, a survey of all current research relevant to nuclear winter (both in the executive branch and in private institutions) and a more critical study aimed at identifying those areas where further work would be most effective. OTA is unlikely to involve itself in basic research, but feels it does have a role to play in reviewing the efforts of others.

Tim Beardsley

\title{
Under-the-counter support
}

THE Netherlands Government budget for 1985 , announced last week, contains a few grains of hope for Dutch scientists - and there may be more to come. Science minister Willem Deetman, while broadly protecting the budgets of the national research council (ZWO) and academy of sciences (KNAW), has offered them a little more (just one per cent) to pay for new positions (such as predoctoral and postdoctoral fellowships). Meanwhile, he has continued to tighten the noose on the universities, once considered the bestfunded in the world. But, it is said in circles close to the government, he is seeking extra funds to pay for the reinstrumentation of laboratories. But why is he doing this outside the budget, who will benefit from it, and by how much? All these questions are matters for speculation.

At ZWO, the small but respected council for basic science, the budget always contains a few per cent extra for re-equipment, but the sum has been too small "for a number of years", says its director, Professor Robert van Lieshout. In the budget this year, ZWO receives DFI 15 million ( $£ 3.5$ million) in this category, around seven per cent of the working budget "but we need ten per cent", says van Lieshout.

Nevertheless van Lieshout is relieved at least to find his net budget uncut. The universities had suffered what they claim to be the maximum possible reductions in recent years, while the research council had been left unscathed; and the Dutch budget minister was demanding more cuts all round. "It's our turn next", said van Lieshout before the budget - but his fears were unfounded.

Moreover, through a budget decision which affects many national institutions, ZWO (and KNAW) find they have a one per cent budget increase to pay for new posts. In ZWO at least, these will be used to provide a few more much-needed postgraduate and postdoctoral fellowships. The Huyghens programme, providing fellowships for high-flyers (20 last year, the first year of the programme), will also be continued by "scraping off" another one per cent of the total ZWO budget. This year, that will pay for around 16 fellowships - although it has been estimated that perhaps another 100 are necessary to maintain the health of science in the Netherlands. 